\title{
Local Treatment for Recurrent Colorectal Hepatic Metastases after Partial Hepatectomy
}

\author{
Anne E. M. van der Pool • Z. S. Lalmahomed • \\ Johannes H. W. de Wilt • Alexander M. M. Eggermont • \\ Jan M. N. IJzermans • Cornelis Verhoef
}

Received: 2 October 2008 / Accepted: 11 December 2008 /Published online: 9 January 2009

(C) 2009 The Author(s). This article is published with open access at Springerlink.com

\begin{abstract}
Objective The objective of the study was to identify patients who may benefit from local treatment in recurrent colorectal liver metastases.

Materials and methods A total of 51 consecutive patients were treated for hepatic recurrence(s) after an initial partial hepatic resection. Surgery was considered as the primary treatment option for eligible patients. Patients with a small liver remnant after major hepatectomy were treated with radiofrequency ablation (RFA) or stereotactic body radiation therapy (SRx). SRx was given as an outpatient, emerging local treatment option for patients with intra-hepatic recurrences not eligible for surgery or RFA. Partial liver resection was performed in 36 patients $(70 \%)$, RFA in ten patients (20\%), and SRx in five patients $(10 \%)$.

Results Median hospital stay was 7 (range, 3-62) days with a morbidity of $16 \%$ without in-hospital death. None of the patients received adjuvant chemotherapy. There was no difference in recurrence or survival between the three treatment modalities. Overall 5-year survival was $35 \%$ with an estimated median survival of 37 months. Patients with a disease-free interval between first hepatectomy and hepatic recurrence less than 6 months did not survive 3 years.

Conclusions Resection, RFA, and SRx can be performed safely in patients with recurrent colorectal liver metastases and offer a survival that seems comparable to primary liver resections of colorectal liver metastases.
\end{abstract}

Keywords Colorectal liver metastases $\cdot$ Recurrent hepatic metastases $\cdot$ Hepatic resection $\cdot$ Radiofrequency ablation . Stereotactic body radiation

\section{Introduction}

Colorectal cancer is one of the most common malignancies and a leading cause of death. Liver metastases develop in

\footnotetext{
A. E. M. van der Pool J. H. W. de Wilt • A. M. M. Eggermont C. Verhoef $(\bowtie)$

Department of Surgical Oncology,

Erasmus University MC-Daniel den Hoed Cancer Center, PO Box 5201, 3008 Rotterdam, AE, The Netherlands

e-mail: c.verhoef@erasmusmc.nl
}

Z. S. Lalmahomed · J. M. N. IJzermans

Division of Transplantation and Hepatic Surgery,

Erasmus University MC,

Rotterdam, The Netherlands
$50-60 \%$ of patients, ${ }^{1,2}$ and surgical resection currently represents the best treatment for long-term survival and even cure in patients with colorectal liver metastases. Despite the curative intent, more than $60 \%$ will suffer from recurrence after liver resection, the liver being the most common location. ${ }^{3}$ Since liver resection has become safer through improvements in surgical techniques and per-operative management, repeat hepatic resection is being more frequently performed in patients with hepatic recurrences. Several studies on repeat hepatic resection have been reported in the last decade. ${ }^{4-9}$ Recent technologic advances have also made local ablative treatments for liver tumors accessible. ${ }^{10}$ Patients with small central recurrences after a prior major liver resection and patients who are poor candidates for surgery are often treated by radiofrequency ablation (RFA). Stereotactic body radiation therapy (SRx) is another emerging local treatment option for patients with intrahepatic malignancies not eligible for surgery or RFA. ${ }^{11}$ 
Unfortunately, most patients who develop a recurrence after colorectal liver surgery cannot undergo secondary procedures. Systemic chemotherapy (CTx) is used in these patients with increasing median survival rates with current multimodality treatments. ${ }^{12,13}$ Approximately 5\% to $10 \%$ of patients who develop hepatic recurrence after liver resection are amenable to a second resection or local ablative treatment. Most reports are based on small populations or on combined populations from several centers. In this article, we report our experience in a single center with local treatment for recurrent liver disease. The purpose of this study was to evaluate prognostic factors for overall, disease-free survival and to identify patients who might benefit most from secondary local treatment.

\section{Patients and Methods}

Between March 1988 and October 2007, 520 partial liver resections were performed in our center because of colorectal liver metastases. Fifty-one patients were treated for hepatic recurrences after a first partial hepatic resection for colorectal liver metastases.

Criteria for repeat liver treatment were similar to those for first hepatectomy: the presence of technically removable metastases (preserving at least two segments of the liver parenchyma), and the possibility of an oncological radical procedure. Surgery was considered as the primary treatment option for eligible patients. Nowadays, surgery provides the best outcome for the treatment of colorectal liver metastases. To date, no randomized trial has been performed between resection versus local ablation. Therefore, in colorectal metastases, surgery is still the gold standard. ${ }^{14,15}$ For patients with a small liver remnant after major hepatectomy, RFA or SRx were alternatives if the metastases were $<3 \mathrm{~cm} .{ }^{10,11}$ RFA was first treatment option, but in case of ill location of the metastases (nearby main vessel and/or bile ducts), SRx was the alternative.

Patients with extrahepatic disease that was resectable were also included in this study.

RFA was performed with a $200-\mathrm{W}$ RF generator and the cluster RF electrode was introduced into the hepatic malignancies during laparotomy or by imaging guidance percutaneously. ${ }^{10} \mathrm{SRx}$ was mostly given in three fractions of $15 \mathrm{~Gy}$, and the prescription isodose was $65 \%$. $^{11}$

Data analyzed included demographics, pathological tumor-node-metastases stage of the primary tumor, maximum size and number of metastases on computed tomography (CT), plasma carcinoembryonic antigen (CEA) level, type of liver surgery, overall duration of hospital stay, complications, radicality, site, and treatment of recurrence.
Overall survival and disease-free survival (DFS) were measured from the start of treatment of hepatic recurrence. The nomenclature and extent of hepatic resection were recorded according to the terminology defined by Couinaud. ${ }^{16}$ We defined a positive surgical margin as the presence of exposed tumor along the line of transaction.

After partial hepatectomy, patients routinely underwent a physical examination and determination of CEA level and abdominal/chest CT or ultrasonography every 4 months for the first year, every 6 months the second year, and once a year thereafter. Endoscopic surveillance was performed after 1 year and thereafter depending on the findings.

The nonparametric log-rank test was used to identify prognostic variables associated with survival after the second liver resection, with significance at $p=0.05$.

\section{Results}

First Partial Liver Resection

Clinical data of the first partial hepatectomy are depicted for all 51 patients in Table 1 . At the time of the first hepatectomy, one patient had extrahepatic disease of the lung and underwent a pulmonary lobectomy. In another patient a peritoneal metastasis was detected during laparotomy and resected simultaneously with the liver metastases. The

Table 1 Clinical Data on the First and Second Local Treatment

\begin{tabular}{|c|c|c|}
\hline & $\begin{array}{l}\text { First hepatectomy } \\
N=51\end{array}$ & $\begin{array}{l}\text { Second local } \\
\text { treatment } N=51\end{array}$ \\
\hline \multicolumn{3}{|l|}{ Neoadjuvant CTx } \\
\hline Yes & 26 & 11 \\
\hline No & 25 & 40 \\
\hline No. of tumors ${ }^{\mathrm{a}}$ & $2(1-8)$ & $1(1-5)$ \\
\hline Size of tumor $(\mathrm{cm})^{\mathrm{a}}$ & $3(1-10)$ & $2.5(1-7)$ \\
\hline $\begin{array}{l}\text { Preoperative CEA-level } \\
(\mu \mathrm{g} / \mathrm{L})^{\mathrm{a}}\end{array}$ & $17(1-5315)$ & $10(1-126)$ \\
\hline \multicolumn{3}{|l|}{ Tumor distribution } \\
\hline Unilobar & 30 & 44 \\
\hline Bilobar & 21 & 7 \\
\hline \multicolumn{3}{|l|}{ Liver surgery } \\
\hline Extended hemihepatectomy & 2 & - \\
\hline Hemihepatectomy & 16 & 6 \\
\hline Extra-anatomic & 33 & 30 \\
\hline RFA & - & 10 \\
\hline SRx & - & 5 \\
\hline Morbidity (\%) & $12(24 \%)$ & $8(16 \%)$ \\
\hline Mortality (\%) & 0 & 0 \\
\hline Hospital stay (days) & 8 & 7 \\
\hline Positive surgical margin (\%) & $7(14 \%)$ & $2(4 \%)$ \\
\hline
\end{tabular}

${ }^{\mathrm{a}}$ Median 
resection margin at permanent section was microscopically not free of tumor in seven patients. There was no in-hospital death, 12 patients had per-operative complications without surgical re-intervention, and median hospital stay was 8 (range 4-72) days.

\section{Intrahepatic Recurrences}

Clinical data of the 51 patients who underwent treatment for recurrent metastases are depicted in Table 1. The median interval between first hepatectomy and recurrent hepatic metastases was 11 (range, 3-78) months. Partial liver resection was performed in 36 patients (70\%), RFA in ten patients $(20 \%$, two open and eight percutaneous procedures) and SRx in five patients $(10 \%)$. One patient showed peritoneal disease, and the omentum was resected. One patient showed ingrowth of the diaphragm, and a partial resection of the diaphragm was performed. Two patients received additional SRx for solitary lung metastases and one patient for a solitary costal metastasis. There was no in-hospital death. Eight patients had per-operative complications without surgical intervention, and median hospital stay for patients who underwent resection or open RFA was 7 (range, 3-65) days. None of the patients were treated with adjuvant CTx.

\section{Follow-Up}

Median follow-up from secondary treatment for recurrences were 22 (3-115) months. Thirty-two patients (63\%) developed a secondary recurrence. Five patients underwent palliative systemic CTx for pulmonary metastases. One patient developed a local recurrence in the pelvis and underwent resection. Of the 26 patients with intra-hepatic recurrence, 14 patients were treated with palliative CTx or analgesic treatment and 12 patients with repeat local treatment. Disease-free survival after treatment of hepatic recurrence was $47 \%$ at 1 year, and estimated median DFS was 11 months.

\section{Survival}

Overall 3-year and 5-year survival rates were 55\% and $35 \%$, respectively, with an estimated median survival of 37 months. The results of univariate analysis of overall 3 -year survival after treatment of recurrent hepatic metastases are depicted in Table 2. Patients with an interval of more than 6 months between first hepatectomy and second local treatment and patients with metastases detected synchronously with the primary tumor have a significantly better survival ( $p=0.01$ and $p=0.006$, respectively). After a median follow-up of 22 months, 18 patients died, and 33
Table 2 Univariate Analysis of Prognostic Factors for Survival after Repeat Treatment for Recurrence of Intrahepatic Disease

\begin{tabular}{|c|c|c|c|}
\hline Prognostic factor & $N(\%)$ & $\begin{array}{l}\text { Survival } \\
3 \text { years }(\%)\end{array}$ & $\begin{array}{l}\text { Significance } \\
(p)\end{array}$ \\
\hline \multicolumn{4}{|l|}{ Age } \\
\hline$\leq 60$ & 25 & 54 & \\
\hline$>60$ & 26 & 56 & 0.57 \\
\hline \multicolumn{4}{|l|}{ Gender } \\
\hline Male & $34(67)$ & 64 & \\
\hline Female & $17(33)$ & 19 & 0.05 \\
\hline \multicolumn{4}{|c|}{ Site of primary tumor } \\
\hline Colon & $31(61)$ & 56 & \\
\hline Rectum & $20(39)$ & 54 & 0.71 \\
\hline \multicolumn{4}{|l|}{ First metastases } \\
\hline Synchronous & 32 & 68 & \\
\hline Metachronous & 19 & 26 & 0.006 \\
\hline \multicolumn{4}{|l|}{ pT primary tumor } \\
\hline $\mathrm{T} 0-2$ & 6 & 100 & \\
\hline T3-4 & 45 & 50 & 0.09 \\
\hline \multicolumn{4}{|l|}{$\mathrm{pN}$ primary tumor } \\
\hline Negative & 26 & 50 & \\
\hline Positive & 25 & 59 & 0.50 \\
\hline \multicolumn{4}{|c|}{ Interval (months) of first hepatectomy to date of recurrence } \\
\hline$\leq 6$ & 6 & 0 & \\
\hline$>6$ & 45 & 62 & 0.01 \\
\hline \multicolumn{4}{|l|}{ Second metastases } \\
\hline \multicolumn{4}{|l|}{ No. of tumors } \\
\hline 1 & 30 & 54 & \\
\hline$>1$ & 21 & 72 & 0.86 \\
\hline \multicolumn{4}{|c|}{ Size of tumor $(\mathrm{cm})$} \\
\hline$\leq 5$ & 47 & 58 & \\
\hline$>5$ & 4 & 33 & 0.85 \\
\hline \multicolumn{4}{|l|}{ Neoadjuvant CTx } \\
\hline Yes & 11 & 64 & \\
\hline No & 40 & 53 & 0.68 \\
\hline \multicolumn{4}{|l|}{ CEA } \\
\hline$\leq 50$ & 43 & 54 & \\
\hline$>50$ & 4 & 100 & 0.66 \\
\hline \multicolumn{4}{|c|}{ Distribution of metastases } \\
\hline Unilobar & 44 & 57 & \\
\hline Bilobar & 7 & 38 & 0.47 \\
\hline \multicolumn{4}{|c|}{ Extrahepatic disease } \\
\hline Absent & 46 & 59 & \\
\hline Present & 5 & 0 & 0.32 \\
\hline \multicolumn{4}{|l|}{ Type of treatment } \\
\hline Resection & 36 & 53 & \\
\hline RFA/SRx & 15 & 59 & 0.71 \\
\hline \multicolumn{4}{|c|}{ Positive lymph nodes } \\
\hline No & 49 & 36 & \\
\hline Yes & 2 & 36 & 0.62 \\
\hline \multicolumn{4}{|c|}{ Margin of hepatectomy } \\
\hline R0 & 34 & 42 & \\
\hline $\mathrm{R} 1$ & 2 & 0 & 0.72 \\
\hline
\end{tabular}


patients are alive of whom 24 patients are alive without disease.

\section{Discussion}

Without treatment, patients with colorectal liver metastases have a life expectancy of less than 1 year. ${ }^{17}$ With the increasingly efficient chemotherapy regimens, median survivals currently reach 16-22 months. ${ }^{12,18}$ In our study group, median overall survival was 37 months after local treatment of the intra-hepatic recurrences. Our study reports overall 3-year and 5-year survival rates of 55\% and $35 \%$ after local treatment of recurrent colorectal liver metastases, which is comparable to the outcome in our series of first hepatectomies that we published previously. ${ }^{19}$ Low morbidity $(16 \%)$ and no in-hospital death showed that repeat local treatment for colorectal hepatic metastases can be performed safely. These results are comparable with those of other studies (Table 3). ${ }^{4-9}$

Improvements in surgical techniques and per-operative management increase the number of repeat hepatic resection in patients with isolated hepatic recurrence. ${ }^{20} \mathrm{~A}$ reduction of blood loss, which is associated with preoperative morbidity and mortality, was obtained over the past decade with a corresponding decrease of transfusion requirements. This was related to an increase in parenchymal-sparing resection, performing of resections with a low central venous pressure, and with the advent of portal pedicle ligation maneuvers. $^{21}$ The extent of liver resection depends on the size, location, distribution, and the relation of the major afferent and efferent vasculatures and bile ducts to liver metastases. More wedge resections can be performed because several recent studies have indicated that a margin less than $1 \mathrm{~cm}$ is not a contraindication to resection of colorectal liver metastases. ${ }^{22-25}$ Moreover, a margin of $1 \mathrm{~mm}$ seems to be appropriate, despite the fact that the pathological report will define the procedure as a microscopic irradical resection. ${ }^{24}$ Current techniques with ultrasonic dissectors aspirate a part of the liver parenchyma interposed between the specimen and the normal liver, making assessment of the true margin difficult.

The rate of wedge resection in our study was higher in repeat hepatectomies than in the initial hepatectomies because the extent of resection at repeat hepatectomy depended on the amount of remnant liver after first hepatectomy. It seems that the extent of hepatic resection does not influence the outcome of secondly resected patients, providing that all metastatic tissue is removed, which is in agreement with the results of Zorzi et al. ${ }^{26}$ A deeper knowledge of the segmental anatomy of the liver $^{16}$ and the routine use of intraoperative ultrasonography has eliminated the need of "blind" extensive resection, therefore limiting the amount of resected parenchyma.

The present study shows that 3-year survival rate is significantly better for those patients with an interval of more than 6 months between first hepatectomy and hepatic recurrence. Patients who had an interval shorter than 6 months did not survive longer than 3 years (median estimated survival 27 months). This is in agreement with the results of Bhattacharjya et al. who suggest that tumors recurring early following liver resection are less likely to be amenable to re-resection because of adverse tumor characteristics and a higher potential for spread of disease. ${ }^{27}$ They concluded in their study that aggressive follow-up during the first 6 months was not advisable because none of the patients could benefit from local treatment. Together with our results, it may be concluded that patients with intrahepatic recurrences within 6 months after partial hepatectomy should be offered systemic CTx because the median survival of patients who were treated with modern systemic

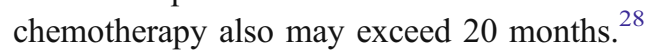

The other significant factor was synchronicity of the metastases of the primary tumor. Patients with synchronous metastases showed a significantly $(p=0.006)$ improved survival after intra-hepatic recurrences that could be treated by local treatment than patients with metachronous disease.

Table 3 Literature Review of Large Series ( $>50$ pts) of Repeat Local Treatment in Patients with Recurrent Colorectal Liver Metastases in the Last 10 Years

\begin{tabular}{|c|c|c|c|c|c|c|c|c|}
\hline \multirow[t]{2}{*}{ Authors } & \multirow[t]{2}{*}{ Year } & \multirow[t]{2}{*}{ No. of centers } & \multirow[t]{2}{*}{ No. of patients } & \multirow[t]{2}{*}{ Mortality (\%) } & \multirow[t]{2}{*}{ Morbidity (\%) } & \multirow{2}{*}{$\begin{array}{l}\text { Median survival } \\
\text { (months) }\end{array}$} & \multicolumn{2}{|l|}{ Survival } \\
\hline & & & & & & & 3 years & 5 years \\
\hline Adam $^{4}$ & 1997 & 1 & 64 & 0 & 19 & 46 & 60 & 41 \\
\hline Sugarbaker $^{7}$ & 1999 & 20 & 170 & NR & 19 & 34 & 45 & 32 \\
\hline Yamamoto $^{9}$ & 1999 & 1 & 70 & 0 & 11 & 31 & 48 & 31 \\
\hline Petrowsky $^{5}$ & 2002 & 2 & 126 & 1.6 & 28 & 37 & 51 & 31 \\
\hline Thelen $^{8}$ & 2006 & 1 & 94 & 3.1 & 23 & NR & 55 & 38 \\
\hline Shaw $^{6}$ & 2006 & 1 & 66 & 0 & 18 & 56 & 68 & 44 \\
\hline Present series & 2008 & 1 & 51 & 0 & 16 & 37 & 55 & 35 \\
\hline
\end{tabular}


A clear explanation cannot be given besides the fact that the number of patients is small.

Despite favorable results of repeat hepatic resection for patients with recurrent colorectal liver metastases, there remains controversy regarding the optimal treatment for such patients. The advent of minimally invasive therapies such as RFA or SRx may offer less procedure-associated morbidity and mortality. A concern is the variable rate of local recurrence that can follow such targeted therapies. Lesions treated with RFA have local recurrence rates of $4 \%$ to $55 \%{ }^{10,29}$ Crude local control rates of $78-100 \%$ are reported in tumor-based analysis after SRx. ${ }^{30}$ RFA has achieved an important role for patients unfit for surgery with small $(<3 \mathrm{~cm})$ liver metastases. Some authors even stated that the time has come to perform a randomized trial between resection and other local ablative methods. ${ }^{31}$ In our center, resection is still the gold standard. ${ }^{15}$ The treatment failure rate after radiofrequency ablation even in small tumors is higher than local recurrence rates after definitive resection. Again, the results of the local ablative treatments are promising, and therefore, local ablation therapies may be applied in patients not suitable for surgery because of ill location of the tumor and/or the physical state of the patients.
In the current study, no difference was found in recurrence or survival in patients treated with resection, RFA, or SRx. In our practice, patients with small central located intra-hepatic recurrences after a prior major liver resection are often treated by RFA. RFA could be performed percutaneously, avoiding the complications associated with partial hepatectomy. RFA and SRx may be used in conjunction with operative resection to increase resectability. Furthermore, these alternatives to surgery may increase the population considered for treatment of hepatic recurrences in case of patients unfit for operation. A possible algorithm for different treatment modalities of recurrent liver metastases is proposed in Fig. 1.

\section{Conclusion}

These repeat local treatments can be performed safely, without greater risk than first liver resections, and offer a survival rate as good as first liver resections. Resection should be the preferred approach, but RFA and SRx are good alternatives with a beneficial outcome. Patients with intra-hepatic recurrences within 6 months after first partial hepatectomy should be offered systemic chemotherapy.

Figure 1 Algorithm.

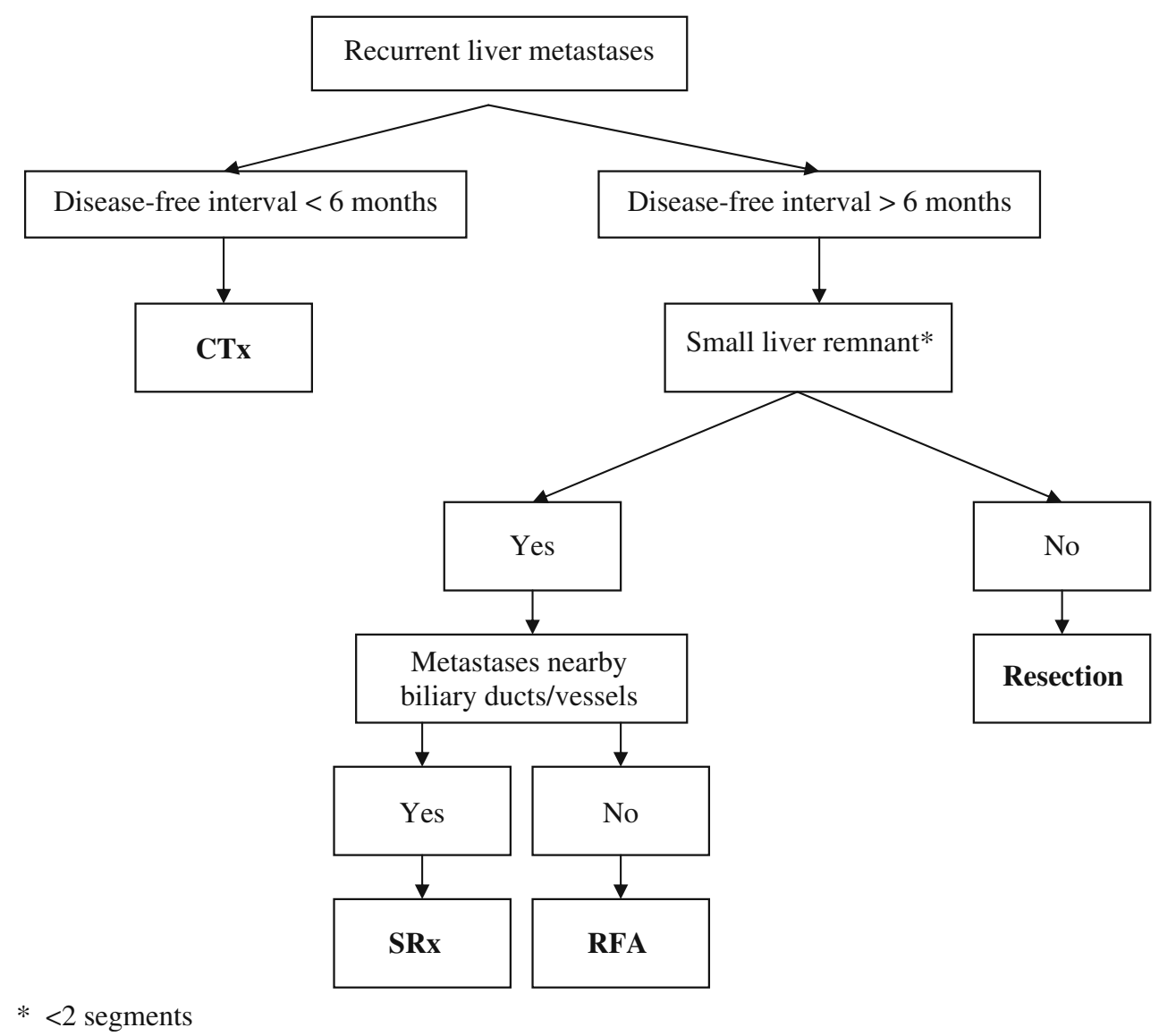


Open Access This article is distributed under the terms of the Creative Commons Attribution Noncommercial License which permits any noncommercial use, distribution, and reproduction in any medium, provided the original author(s) and source are credited.

\section{References}

1. Scheele J, Stang R, Altendorf-Hofmann A, Paul M. Resection of colorectal liver metastases. World J Surg 1995;19(1):59-71. doi:10.1007/BF00316981.

2. Stangl R, Altendorf-Hofmann A, Charnley RM, Scheele J. Factors influencing the natural history of colorectal liver metastases. Lancet 1994;343(8910):1405-1410. doi:10.1016/S0140-6736(94) 92529-1.

3. Simmonds PC, Primrose JN, Colquitt JL et al. Surgical resection of hepatic metastases from colorectal cancer: a systematic review of published studies. Br J Cancer 2006;94(7):982-999. doi:10.1038/sj.bjc.6603033.

4. Adam R, Bismuth H, Castaing D et al. Repeat hepatectomy for colorectal liver metastases. Ann Surg 1997;225(1):51-60. discussion 60-2. doi:10.1097/00000658-199701000-00006.

5. Petrowsky H, Gonen M, Jarnagin W et al. Second liver resections are safe and effective treatment for recurrent hepatic metastases from colorectal cancer: a bi-institutional analysis. Ann Surg 2002;235(6):863-871. doi:10.1097/00000658-200206000-00015.

6. Shaw IM, Rees M, Welsh FK et al. Repeat hepatic resection for recurrent colorectal liver metastases is associated with favourable long-term survival. Br J Surg 2006;93(4):457-464. doi:10.1002/ bjs. 5323 .

7. Sugarbaker PH. Repeat hepatectomy for colorectal metastases. J Hepatobiliary Pancreat Surg 1999;6(1):30-38. doi:10.1007/ s005340050081.

8. Thelen A, Jonas S, Benckert $\mathrm{C}$ et al. Repeat liver resection for recurrent liver metastases from colorectal cancer. Eur J Surg Oncol 2007;33(3):324-328. doi:10.1016/j.ejso.2006.10.016.

9. Yamamoto J, Kosuge T, Shimada K et al. Repeat liver resection for recurrent colorectal liver metastases. Am J Surg 1999;178 (4):275-281. doi:10.1016/S0002-9610(99)00176-2.

10. de Meijer VE, Verhoef C, Kuiper JW et al. Radiofrequency ablation in patients with primary and secondary hepatic malignancies. J Gastrointest Surg 2006;10(7):960-973. doi:10.1016/j. gassur.2006.03.003.

11. Mendez Romero A, Wunderink W, van Os RM et al. Quality of life after stereotactic body radiation therapy for primary and metastatic liver tumors. Int J Radiat Oncol Biol Phys 2008;70 (5):1447-1452.

12. Tournigand C, Andre T, Achille E et al. FOLFIRI followed by FOLFOX6 or the reverse sequence in advanced colorectal cancer: a randomized GERCOR study. J Clin Oncol 2004;22(2):229-237. doi:10.1200/JCO.2004.05.113.

13. Zampino MG, Magni E, Massacesi $C$ et al. First clinical experience of orally active epidermal growth factor receptor inhibitor combined with simplified FOLFOX6 as first-line treatment for metastatic colorectal cancer. Cancer 2007;110(4):752-758. doi: $10.1002 /$ cncr.22851.

14. Curley SA. Radiofrequency ablation versus resection for resectable colorectal liver metastases: time for a randomized trial? Ann Surg Oncol 2008;15(1):11-13. doi:10.1245/s10434-007-9668-1.

15. de Meijer VE, Ijzermans JN, Verhoef C. A place for radiofrequency ablation in the treatment of resectable colorectal liver metastases? Ann Surg Oncol 2008;15(7):2063. doi:10.1245/ s10434-008-9843-z author reply 2064-5.
16. Couinaud C. Liver anatomy: portal (and suprahepatic) or biliary segmentation. Dig Surg 1999;16(6):459-467. doi:10.1159/ 000018770 .

17. McMillan DC, McArdle CS. Epidemiology of colorectal liver metastases. Surg Oncol 2007;16(1):3-5. doi:10.1016/j.suronc. 2007.04.008.

18. Falcone A, Ricci S, Brunetti I et al. Phase III trial of infusional fluorouracil, leucovorin, oxaliplatin, and irinotecan (FOLFOXIRI) compared with infusional fluorouracil, leucovorin, and irinotecan (FOLFIRI) as first-line treatment for metastatic colorectal cancer: the Gruppo Oncologico Nord Ovest. J Clin Oncol 2007;25 (13):1670-1676. doi:10.1200/JCO.2006.09.0928.

19. Dols LF, Verhoef C, Eskens FA, Schouten O, Nonner J, Hop WC, Méndez Romero A, De Man RA Van der Linden, Dwarkasing R, IJzermans JN. Improvement of survival after resection of colorectal liver metastases. Ned Tijdschr Geneeskd. 2008; in press.

20. DeMatteo RP, Fong Y, Jarnagin WR, Blumgart LH. Recent advances in hepatic resection. Semin Surg Oncol 2000;19(2):200 207. doi:10.1002/1098-2388(200009)19:2<200::AID-SSU11>3.0. $\mathrm{CO} ; 2-\mathrm{M}$.

21. Jarnagin WR, Gonen $M$, Fong $\mathrm{Y}$ et al. Improvement in perioperative outcome after hepatic resection: analysis of 1,803 consecutive cases over the past decade. Ann Surg 2002;236 (4):397-406. doi:10.1097/00000658-200210000-00001 discussion $406-7$.

22. Are $\mathrm{C}$, Gonen $\mathrm{M}$, Zazzali $\mathrm{K}$ et al. The impact of margins on outcome after hepatic resection for colorectal metastasis. Ann Surg 2007;246(2):295-300. doi:10.1097/SLA.0b013e31811ea962.

23. Figueras J, Burdio F, Ramos E et al. Effect of subcentimeter nonpositive resection margin on hepatic recurrence in patients undergoing hepatectomy for colorectal liver metastases. Evidences from 663 liver resections. Ann Oncol 2007;18(7):1190-1195. doi:10.1093/annonc/mdm106.

24. Pawlik TM, Scoggins CR, Zorzi D et al. Effect of surgical margin status on survival and site of recurrence after hepatic resection for colorectal metastases. Ann Surg 2005;241(5):715-722. doi:10.1097/01.sla.0000160703.75808.7d discussion 722-4.

25. Pawlik TM, Vauthey JN. Surgical margins during hepatic surgery for colorectal liver metastases: complete resection not millimeters defines outcome. Ann Surg Oncol 2008;15(3):677-679. doi: 10.1245/s10434-007-9703-2.

26. Zorzi D, Mullen JT, Abdalla EK et al. Comparison between hepatic wedge resection and anatomic resection for colorectal liver metastases. J Gastrointest Surg 2006;10(1):86-94. doi:10.1016/j. gassur.2005.07.022.

27. Bhattacharjya S, Aggarwal R, Davidson BR. Intensive follow-up after liver resection for colorectal liver metastases: results of combined serial tumour marker estimations and computed tomography of the chest and abdomen - a prospective study. $\mathrm{Br}$ J Cancer 2006;95(1):21-26. doi:10.1038/sj.bjc.6603219.

28. Benoist S, Pautrat K, Mitry E et al. Treatment strategy for patients with colorectal cancer and synchronous irresectable liver metastases. Br J Surg 2005;92(9):1155-1160. doi:10.1002/bjs.5060.

29. Sutherland LM, Williams JA, Padbury RT et al. Radiofrequency ablation of liver tumors: a systematic review. Arch Surg 2006;141 (2):181-190. doi:10.1001/archsurg.141.2.181.

30. Katz AW, Carey-Sampson M, Muhs AG et al. Hypofractionated stereotactic body radiation therapy (SBRT) for limited hepatic metastases. Int J Radiat Oncol Biol Phys 2007;67(3):793-798. doi:10.1016/j.ijrobp.2006.10.025.

31. Mulier S, Ni Y, Jamart $J$ et al. Radiofrequency ablation versus resection for resectable colorectal liver metastases: time for a randomized trial? Ann Surg Oncol 2008;15(1):144-157. doi:10.1245/ s10434-007-9478-5. 